was attributed to PsA, IL-21 increase $(90.6 \pm 158)$ was found in AS group. Nevertheless, there was no significant difference between patients' groups in the tested cytokines concentrations. Despite of less active disease in PsA than in AS patients (ASDAS ${ }_{\text {CRP }} 2.76 \pm 1$ vs $\left.3.44 \pm 0.89\right)$, PsA patients had higher Al $(4.44 \pm 1.3$ vs $3.37 \pm 1$ ). Importantly, in both AS and PsA groups, OPG concentration positively correlated with SCORE values ( $R=0.613$ and 0.792 , respectively). However, in PsA patients also IL-18 concentration showed similar noxious associations, correlating positively with $\mathrm{Al}(R=0.705)$, and triglycerides level $(R=0.679)$ but inversely with $\mathrm{HDL}$ level $(R=-0.525)$ and $\mathrm{HDL} / \mathrm{LDL}$ ratio $(R=-0.623)$. On the other hand, neither in AS nor in PsA patients the cytokines of IL-17/L-23 axis were significantly related to $\mathrm{CV}$ risk.

Conclusions: By showing positive correlation of serum OPG with CV risk expressed by SCORE in AS and PSA patients we support opinion of an important role of OPG in CVD pathogenesis. Our results may also suggest that in PsA patients IL-18, up-regulated owing to skin inflammation, contributes to dyslipidemia and thus further increases CV risk.

Acknowledgements: Supported by the NIGRiR, Warsaw, Poland (grants No $\mathrm{S} / 16$ and $\mathrm{S} / 2$ ).

Disclosure of Interest: None declared

DOI: 10.1136/annrheumdis-2017-eular.3475

\section{AB0734 EVALUATION OF CARDIOVASCULAR RISK PROFILES IN A POPULATION OF PATIENTS WITH ANKYLOSING SPONDYLITIS: A CROSS-SECTIONAL STUDY}

A. Ghrbel ${ }^{1}$, M. Turki ${ }^{1}$, A. Feki ${ }^{2}$, B. Belhasan ${ }^{3}$, R. Akrout ${ }^{2}$, M. Chtourou $^{1}$, M. Neifar ${ }^{1}$, H. Fourati ${ }^{2}$, S. Baklouti ${ }^{2}$, F. Ayedi ${ }^{1}$. ${ }^{1}$ Unit of Research "Molecular Bases of Human Diseases", 12ES17, Sfax Medicine University Biochemistry laboratory Habib Bourguiba Hospital; ${ }^{2}$ Hedi Chaker Hospital; ${ }^{3}$ Unit of Research "Molecular Bases of Human Diseases", 12ES17, Sfax Medicine University, Sfax, Tunisia

Background: ankylosing spondylitis (AS), like the other chronic inflammatory rheumatic diseases, is considered to have higher cardiovascular (CV) risk (1). The Etiopathogenesis is not clearly defined.

Objectives: assess the early biological markers of atherosclerosis in Tunisian patients with AS compared with healthy controls and evaluate the relationship between Systematic Coronary Risk Evaluation (SCORE) for CV-related mortality and biological markers (2).

Methods: This was a cross-sectional study conducted since June 2015 until October 2016 including patients with AS in the South of Tunisia and matched controls with sex, age, body mass index (BMI) and smoking. Patients diagnosed with AS should fulfill the modified New York criteria. For patients and controls, we measured total cholesterol (TC), high density lipoprotein (HDL) cholesterol, triglycerides, apolipoprotein (Apo) Al, ApoB, lipoprotein (a) [Lp(a)] and C-Reactive Protein (CRP). Low-density lipoprotein (LDL) cholesterol was calculated with the Friedewald formula. SCORE was calculated through the use of sex, age, systolic pressure, smoking and TC. Comparisons were performed using two sample t-tests for parametric values and Wilcoxon Mann-Whitney Test for non-parametric values. Correlation analyses were performed with Spearman rank.

Results: Overall 79 patients with AS and 79 controls were included. The mean age was ( $43.81 \pm 14.29$ vs $44,27 \pm 14$ years). The sex ratio $(M / F)$ was $2 / 1$ and the mean BMI was $\left(25.9 \pm 5.3\right.$ vs $\left.25.76 \pm 3.5 \mathrm{~kg} / \mathrm{m}^{2}\right)$. AS patients had significantly lower levels of $\mathrm{HDL}$ and TC and a higher level of CRP and atherogenic index (TC/HDL, ApoB/ApoA). AS patients had higher CV mortality than controls $(1.1 \pm 1.8$ vs $0,51 \pm 1.13 \%, p=0.01)$. The frequency of high cardiovascular risk was higher in AS patients ( 5 vs $2, p=0.4)$. The correlation between SCORE's risk and biological markers were positive with TC, LDL, Lp (a), TC/HDL ratio and LDL/HDL ratio. Conclusions: AS patients are at a greater cardiovascular risk due to a higher CRP rate, atherogenic index and 10-year risk SCOREs of CV mortality. So, the dyslipidaemia and inflammation could be the aetiology of cardiovascular risk.

References:

[1] Mathieu S, Soubrier M. Le risque cardiovasculaire dans la spondyloarthrite axiale. Presse Med. 2015:44(9):907-11.

[2] Conroy RM, Pyörälä K, Fitzgerald AP, Sans S, Menotti A, De Backer G, et al. Estimation of ten-year risk of fatal cardiovascular disease in Europe: the SCORE project. Eur Heart J. 2003 Jun;24(11):987-1003.

Disclosure of Interest: None declared

DOI: 10.1136/annrheumdis-2017-eular.6936

\section{AB0735 EVALUATION OF PSYCHOLOGICAL STATE OF PATIENTS WITH ANKYLOSING SPONDYLITIS: REGIONAL REGISTRY AS A TOOL FOR IMPROVEMENT OF MANAGEMENT}

S. Lapshina, D. Abdulganieva, L. Myasoutova. Kazan State Medical University, Kazan, Russian Federation

\section{Background:}

According to modern conception "T2T" a patient with ankylosing spondylitis (AS) takes an active part in the disease treatment that determines the importance of his psychological state.

Objectives: To evaluate interconnection between the psychological state of the patient with AS and the disease course.
Methods: Within the regional registry which is a part of epidemiological study of clinical diversity of AS in Russian population, 40 patients (32 males and 8 females) at the age of 21 to 56 years (average age $40,3 \pm 10,0$ ) were examined. The average disease duration on the day of examination was 12,7+9,9 years, BASDAI - 5,54 $\pm 1,8, \mathrm{BASFI}-5,34 \pm 2,48$. Functional status (range of motion) was evaluated by means of BASMI. EQ-5D questionnaire was used for psychological state evaluation.

Results: A total of $17(42,5 \%)$ patients had anxiety and depression: moderate $-15(88,2 \%)$, severe $-2(11,8 \%)$ responders. With the disease duration of less than 5 years propensity for depression and anxiety was noted by 6 out of 11 $(54,5 \%)$ patients, 5 to 10 years -2 out of $12(16,7 \%)$, more than 10 years -9 out of $17(52,9 \%)$.

In patients with mild disease activity anxious and depressive states were not observed, with moderate disease activity they were revealed in 3 out of 7 patients $(42,8 \%)$, with severe activity - in 9 out of $21(42,8 \%)$, with very severe activity in 5 out of $10(50 \%)$ responders.

Among the patients without limitation of motion (BASFI) anxiety and depression was revealed in 2 out of $11(18,2 \%)$, with moderate limitation -6 out of $18(33,3 \%)$, with severe limitation -9 out of $11(81,8 \%)$ patients. According to BASMI 1 out of 2 patients without limitation of motion had anxiety and depression, 6 out of 19 $(31,5 \%)$ - with moderate limitation and 10 out of $19(52,6 \%)$ with severe limitation. The direct correlation was revealed between EQ-5D score and BASFI $(r=0,996)$ and between EQ-5D and BASDAI $(r=0,855)$, concurrently such correlation was absent between $\mathrm{BASMI}$ and $\mathrm{EQ}-5 \mathrm{D}$.

Among the patients without anxious and depressive states 14 out of $23(60,8 \%)$ patients take NSAIDs regularly while among the patients who noted propensity for anxiety and depression only 7 out of $17(41,17 \%)$ take NSAIDs regularly.

Conclusions: Patients with short (less than 5 years) and long (more than 10 years) AS duration, severe disease activity and functional limitation are more prone to anxiety and depression. Patients with anxious and depressive states are less compliant with therapy which influences its efficacy. These data should be considered when the programs of AS patients' management are developed.

Disclosure of Interest: None declared DOI: 10.1136/annrheumdis-2017-eular.3959

\section{AB0736 THE DATA OF CENTRAL AORTIC PRESSURE AND PULSE WAVE VELOCITY IN PATIENTS WITH ANKYLOSING SPONDYLITIS}

T. Aksenova ${ }^{1,2}$, N. Ivashhenko ${ }^{1,2}$, S. Tsarenok ${ }^{1}$, V. Gorbunov ${ }^{1}$, P. Gromov ${ }^{2}$ ${ }^{1}$ therapy, Chita State Medical Academy; ${ }^{2}$ The hospital within the Russian Railroad Network, Chita, Russian Federation

Background: Pulse Wave Velocity (PWV) is the main determinant of arterial stiffness. In recent years the increased arterial stiffness in Ankylosing Spondylitis was shown [1]. The most of investigations of arterial stiffness in ankylosing spondylitis were performed on the treatment by anti TNF-therapy [2]. However, today this issue has not been adequately studied.

Objectives: To evaluate the data of central aortic pressure and PWV and their relationship with Ankylosing Spondylitis.

Methods: 49 patients with Ankylosing Spondylitis aged between 19 and 60 (mean age 39.6 \pm 10.6 ) were examined. This group (group 1) included 38 men, 11 woman. Ankylosing Spondylitis Disease Activity Score (ASDAS-CRP) was 3.11 \pm 0.55 . Duration of Ankylosing Spondylitis was from 0.5 to 20 years (mean $5.87 \pm 4.76$ years). X-ray stage sacroiliac joints (according Modified New York Criteria) was $2.59 \pm 1.42$. The control group included 33 healthy individuals. The groups were similar in age and sex. 10 patients with ankylosing spondylitis have history of arterial hypotension, however, at the time of inclusion in this study their blood pressure was stabilized. The groups did not differ by office blood pressure parameters and heart rate. Indicators of central aortic pressure and PWV were determined by applanation tonometry by SphygmoCor, Australia. For statistical analysis we used Mann-Whitney criteria and Spirmen correlation method. The study was based on GCP principles.

Results: Increased levels of central systolic blood pressure $(118.02+14.02$ vs $101.1 \pm 10.2, p=0.00001)$, central diastolic blood pressure $(80.23 \pm 11.86$ vs $71.8 \pm 7.3, p=0,001)$ were determined in patients with Ankylosing Spondylitis.

Patients with Ankylosing Spondylitis demonstrated the increase in central mean pressure compared to control groop on $17.2 \%$ (108.5 \pm 13.6 vs $92.6 \pm 9.4$ $\mathrm{p}=0.0001$ ). Pulse Wave Velocity (PWV) in the carotid-femoral segment in patients with ankylosing spondylitis was $6.5 \pm 1.3 \mathrm{~m} / \mathrm{sec}$ vs $5.2 \pm 0.96 \mathrm{~m} / \mathrm{sec} \quad(p=0.0001)$ in the control group. The levels of augmentation pressure and Subendocardial viability ratio (SERV) were similar in the examined groups.

PWV was directly correlated with trangulus-to-wall $(r=0,41 ; p=0,005)$ and with $X$-ray stage of sacroilititis $(r=0,31 ; p=0,043)$ and negative correlated with Lumbar flexion (Shober test) $(r=-0,38 ; p=0,009)$.

Conclusions: Increasing indicators of arterial stiffness, such as, PWV, central systolic blood pressure, central diastolic blood pressure, central mean pressure were determined in patients with Ankylosing Spondylitis. The relationship between clinical data, X-ray stage and PWV was demonstrated.

\section{References:}

[1] Berg I., Van der Heijde D., Dagfinrud H., Seljeflot I., Olsen I. C., Kvien T., Semb A., Provan S. Disease activity in ankylosing spondylitis and associations to markers of vascular pathology and traditional cardiovascular disease risk 